\title{
Comparison of In Situ Humidity Data from Aircraft, Dropsonde, and Radiosonde
}

\author{
A. K. Vance, J. P. Taylor, T. J. Hewison, and J. Elms \\ Met Office, Exeter, United Kingdom
}

(Manuscript received 14 January 2003, in final form 3 November 2003)

\begin{abstract}
Results are presented from the Measurement of Tropospheric Humidity (MOTH) Tropic and MOTH Arctic airborne field experiments, comparing a number of in situ humidity measurements. Good agreement is shown between the Total Water Content probe on board the C-130 aircraft, and the Vaisala RS90 and "new" Vaisala RS80 radiosondes; "old" Vaisala RS80 radiosondes and Vaisala RD93 dropsondes show the dry bias noted by others. An empirical correction for RD93 dry bias is presented and is shown to produce good results with both MOTH and non-MOTH data. It was concluded that the aircraft and corrected dropsonde data agree $(1 \sigma)$ to \pm 1 $\mathrm{g} \mathrm{kg}^{-1}$; these limits are due to atmospheric variability. The possibility of temperature measurement errors producing errors in RD93 relative humidities is not significant compared to atmospheric variability. Meteolabor Snow White radiosondes are shown to exhibit a wet bias at high and low mixing ratios and possible reasons are discussed. Intercomparisons between the RS90s and other instruments, partitioned by day-night and by experiment, suggest deficiencies in RS90 daytime radiation corrections.
\end{abstract}

\section{Introduction}

Water vapor is well established as the most important greenhouse gas and hence is crucially important in determining the radiation budget of the atmosphere. Its vertical distribution has a significant impact on local radiative heating and cooling, and on the net fluxes at the surface and the top of the atmosphere. Its threedimensional distribution has a large impact on the dynamics and thermodynamics of the atmosphere and also controls the distribution of clouds. A thorough understanding of the distribution of water vapor is therefore important to our monitoring and understanding of climate change, to our ability to interpret data from future satellite instruments, and to operational numerical weather prediction processes.

In 1999 the U.K. Met Office carried out two Measurement of Tropospheric Humidity (MOTH) field experiments, MOTH Tropic and MOTH Arctic, to investigate relevant radiative transfer issues using a microwave radiometer, the Microwave Airborne Radiometer Scanning System (MARSS; McGrath and Hewison 2001), and a mid-infrared interferometer, the Airborne Research Interferometer Evaluation System (ARIES; Wilson et al. 1999), fitted to the Meteorological Research Flight (MRF) C-130 aircraft. The detailed in situ humidity measurements required for this exercise af-

Corresponding author address: A. K. Vance, Met Office, FitzRoy Road, Exeter, Devon EX1 3PB, United Kingdom.

E-mail: alan.vance@metoffice.com forded the opportunity to intercompare five hygrometers in both tropical and subarctic conditions.

The value of data from radiosondes and dropsondes is well known and, despite the ongoing developments in satellite meteorology, data from radiosondes are, and will continue to be, relied on for routine observations, research, and satellite validation work, despite shortcomings in these data (Guichard et al. 2000; Nash et al. 2003; Wang et al. 2002; Weckwerth et al. 1999). Anderson et al. (2000) and Baker and Eskridge (2000) have investigated the effect on numerical weather prediction of reducing the number of radiosonde observations and found that this causes a significant reduction in the quality of forecast produced. Other researchers (Szunyogh et al. 1999, 2000, and references therein; Amstrup and Huang 1999; Cardinali 2000) have reported significant improvements in numerical weather prediction during the Fronts and Atlantic Storm Tracks Experiment (FASTEX), Tropical Cyclones 98, the North Pacific Experiment (NORPEX), and the Winter Storms Reconnaissance Program (WRS99) resulting from the inclusion of data from extra dropsondes and radiosondes launched in key locations during these experiments.

Differences exist between various sonde types currently in use, and accurate measurements of upper-air humidity (especially at low temperatures) are lacking (Elliot and Gaffen 1991; Garand et al. 1992; Leiterer et al. 1997; Gérard and Saunders 1999). Jaubert et al. (1999) also note differences between sensors and a lack of opportunity to compare dropsondes and radiosondes during FASTEX.

In this paper we present the results of this intercom- 
parison (section 2) and propose a simple empirical scheme for the correction of dry bias seen in the dropsondes used during the MOTH experiments (section 3).

\section{Comparison of in situ humidity data}

\section{a. Summary of instruments compared}

The Total Water Content (TWC) probe is a Lyman$\alpha$ absorption hygrometer developed by the Met Office for use on its C-130 aircraft. Its operating range, accuracy, and resolution are quoted as $0-20, \pm 0.15$, and $\pm 0.005 \mathrm{~g} \mathrm{~kg}^{-1}$, respectively (Nicholls et al. 1990). The TWC is calibrated postflight, using data from an onboard General Eastern 1011B chilled-mirror hygrometer (Ström et al. 1994). Note that although this instrument will measure the combined amount of water in all phases, it may be regarded as a hygrometer in this case because the data considered were gathered only in cloud-free air.

The Vaisala RD93 (revision B) is a dropsonde developed by the National Center for Atmospheric Research (NCAR) in collaboration with Deutschen Zentrum für Luft- und Raumfahrt (DLR) and manufactured by Vaisala Oyj under license. Humidity measurement is by means of a pair of unheated "H-Humicap" capacitative sensors. Relative humidity resolution is quoted as $1 \%$ and the uncertainty in soundings as 5\% (Vaisala 2002a).

The Vaisala RS90 is a balloon-borne radiosonde having a pair of alternately heated H-Humicap sensors. The specifications of these are the same as for the RD93 (Vaisala 2002b).

The Vaisala RS80-H is a balloon-borne radiosonde with a single unheated H-Humicap. Range and resolution are the same as for the RS90 but the repeatability and reproducibility are quoted as $2 \%$ and $<3 \%$, respectively (Vaisala 2002c). RS80 radiosondes from two different calibration batches were used during MOTH Tropic. "Old" shall be used to refer to those calibrated in March 1997 and "new" to those calibrated in January 1999.

The Meteolabor Snow White is a low-cost chilledmirror dewpoint-frost point hygrometer designed for radiosonde use. As the Snow Whites only report dewor frost point, in the MOTH experiments RS90 temperature measurements were used to calculate mass mixing ratios. Relative humidity (dependent on ambient temperature) and mirror temperature ranges are quoted as $2 \%-100 \%$ and $-80^{\circ}$ to $+40^{\circ} \mathrm{C}$, respectively (Meteolabor 2001); accuracy of mirror temperatures is not stated but is believed to be $0.1 \mathrm{~K}$ when used with the RS90 (R. Maag 2003, personal communication).

\section{b. Selection of data}

The greatest potential source of error in these intercomparisons is likely to arise as a result simply of the various instruments sampling air with a different water vapor mass mixing ratio structure (hereafter, "humidity structure"). It is possible neither to "chase" a dropsonde down with the aircraft (as such a spiral descent would result in unacceptable operating conditions for the TWC) nor to chase an ascending balloon. In many cases it will be obvious from inspection if two vertical profiles were measured in air with the same or different humidity structures. Confusion may, however, arise in two ways that are not immediately obvious: 1) if the humidity structures are actually different, but differences in the measuring instruments are such that they (at least partially) offset otherwise obvious discrepancies, and 2) if the humidity structures are identical but not perceived as such because of differences between the measuring instruments.

The following data selection strategy was adopted for the purposes of this instrument intercomparison. Any potential intercomparisons between instruments were rejected if their start or launch times were separated by $2 \mathrm{~h}$ or more. Aircraft profiles were recorded during ascents or descents along one or more straight flight paths. The furthest extremities of the longest of these profiles (in the horizontal plane) in each of the experiments were used to define the maximum acceptable displacement of any two measurements; this was $140 \mathrm{~km}$ in the case of MOTH Tropic, $230 \mathrm{~km}$ for MOTH Arctic. These criteria do not in themselves guarantee that the two measurements being compared will be of the same humidity structure, and the situation will still arise where the humidity structure at one or more levels in a profile differs significantly between the two instruments due to atmospheric effects rather than instrumental ones; these occurrences were handled as part of the comparison process (section 2c).

In all cases Snow Whites were flown on the same balloon as an RS90, thus guaranteeing measurements of the same humidity structure. During MOTH Tropic, RS80s were also flown with RS90s, but during MOTH Arctic the RS80s were flown separately. In the case of such dual flights, unless there was evidence of one of the sondes malfunctioning in a manner that would have been apparent had it been flown solo, the entire profile was used without question.

Table 1 shows the numbers of comparisons with the Vaisala RS90. The choice of the RS90 as a standard for the purposes of this study should not be taken to imply any a priori assumption of greater accuracy on the part of the authors. Also shown are the number of comparisons of the TWC with RD93 dropsondes. As a result of the application of these data selection criteria, a significant quantity of data from the MOTH Arctic experiment, where the weather was more variable, was rejected. Data from a subsequent flight (number A814, near Scarborough, United Kingdom) have been included in this intercomparison as it included specific intercomparison of the aircraft and dropsondes, and data recorded at very low mixing ratios and relatively low temperatures, were included. 
TABLE 1. Numbers of profile pairs involved in intercomparisons with (left) RS90 and (right) TWC.

\begin{tabular}{lccccccc}
\hline \hline RS90 & RD93 & TWC & Old RS80 & New RS80 & Snow White & TWC & RD93 \\
\hline Tropic & 16 & 17 & 7 & 17 & 17 & Tropic & $6+7 *$ \\
Arctic & 11 & 13 & No data & 7 & 8 & Arctic & 6 \\
Day & 23 & 26 & 6 & 20 & 17 & & \\
Night & 4 & 4 & 1 & 4 & 8 & & \\
\hline
\end{tabular}

* Intercomparisons from flight A814.

\section{c. Comparison and results}

The comparisons were carried out in the following way. The data from pairs of profiles, selected as described above, were interpolated onto a 1-hPa grid to permit comparison of the data at similar altitudes. The lowest vertical resolutions recorded were from the balloon-borne instruments and were better than $1 \mathrm{hPa}$. Comparisons were carried out over the maximum altitude range for which there were good data available from both instruments in the sonde/sonde or sonde/aircraft pair. Altitude ranges were typically surface to 24 $\mathrm{km}$ for balloon-borne comparisons and surface to 7-8 $\mathrm{km}$ for those involving dropsonde or aircraft data. The gridded sonde relative humidities were then converted to a mass mixing ratio (all mass mixing ratios referred to are with respect to dry air). Because the Vaisala sondes report relative humidity, the TWC measures the mass mixing ratio, and the Snow Whites measure dewpoint/frost point, it was necessary to convert the humidity data into a common domain. A mass mixing ratio was chosen, in preference to relative humidity or dewpoint, because it is a measure of water vapor alone and not a function of temperature. In processing the Snow White data, $-25^{\circ} \mathrm{C}$ was used for the dewpoint/frost point transition rather than the manufacturer's assumption of $0^{\circ} \mathrm{C}$. The role of temperature in the production of the relative humidities reported by the Vaisala sondes has been considered (A. K. Vance 2004, unpublished manuscript), and the magnitude of humidity errors resulting from incorrect measurement of temperature was found not to be significant compared to the spread of data points seen here, which results from atmospheric variability [note that this is not a recommendation against correcting the known temperature lag of dropsondes after Hock and Franklin (1999)].

At each pressure level, the mean and difference of the two profiles were calculated. Data at levels where the difference between the two mixing ratios exceeded $50 \%$ of their mean (corresponding to 3 times the maximum anticipated bias) at the same level were deemed to be measurements of different humidity structures and removed from the comparison. It has been found that this criterion is not critical. The two sets of mass mixing ratio for each profile were then plotted as [other instrument]/-minus-RS90 versus RS90, except in the case of the comparison of the dropsondes and TWC, in which the TWC was taken as the reference instrument. In each case the solid line indicates the mean of the difference between the instruments (calculated in equal-sized bins), with the dashed lines above and below, respectively, indicating this mean plus and minus one standard deviation. Note that owing to the distribution and numerical range of the data presented, these are plotted on split axes: the abscissas are continuous across both subaxes, with the left-hand part being logarithmic and the right-hand part being linear. All ordinates are linear, and where no scale is explicitly given for the ordinate of the right-hand axes, it is identical to that given on the left.

\section{1) Total WATER CONTENT PROBE AND RS90 PROFILES}

There is good agreement between the TWC and the RS90s at all mixing ratios (Fig. 1); no significant dif-

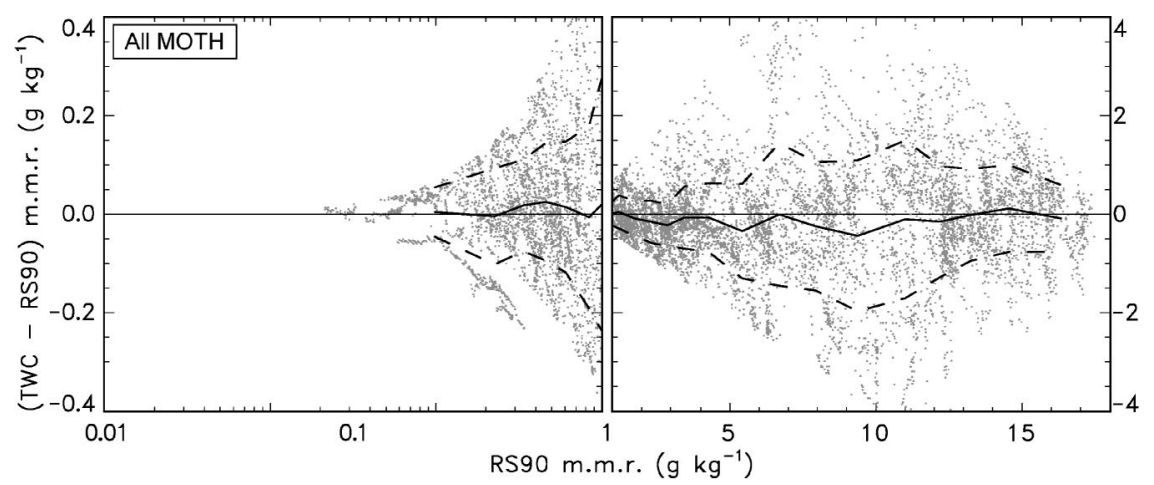

FIG. 1. Comparison of all MOTH TWC and RS90 data, showing good agreement at all mixing ratios. 


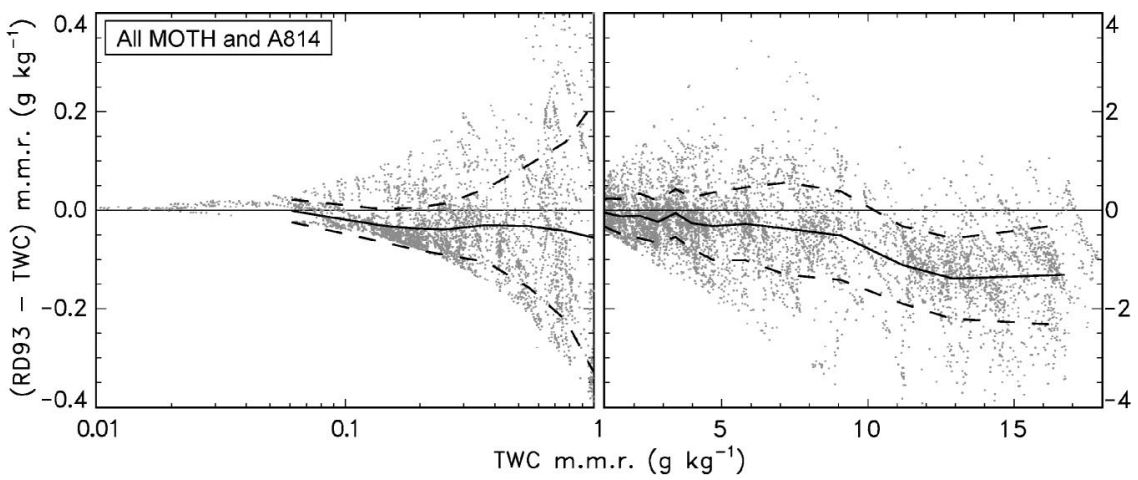

FIG. 2. Comparison of all MOTH and A814 TWC and RD93. RD93 shows dry bias that becomes significant at mixing ratios greater than $10 \mathrm{~g} \mathrm{~kg}^{-1}$.

ferences are seen when the data are partitioned according to experiment (Tropic or Arctic) or whether recorded by day or night. It should be noted that the quality of the comparison at low RH will be compromised by the lack of precision $(1 \% \mathrm{RH})$ in the Vaisala sensors.

\section{2) Total WATER CONTENT PROBE AND RD93 PROFILES}

Reasonable agreement can be seen at lower mixing ratios, but the dropsondes clearly read lower than the TWC at higher mixing ratios (Fig. 2). The difference is approximately $9 \%$ and becomes significant $(1 \sigma)$ above $10 \mathrm{~g} \mathrm{~kg}^{-1}$. The mean minus $1 \sigma$ lies beyond the limit of the data between 0.07 and $0.16 \mathrm{~g} \mathrm{~kg}^{-1}$ due to the RD93 data not being normally distributed at low relative humidity.

\section{3) RD93 AND RS90 PROFILES}

MOTH Tropic shows reasonable agreement throughout the range, with the means not lying consistently more than one standard deviation from the zero difference, but there is, nevertheless, a clear tendency for the dropsonde to report lower mixing ratio than the RS90 above $3 \mathrm{~g} \mathrm{~kg}^{-1}$ (Fig. 3, top row). In MOTH Arctic comparisons the bias is quite clearly seen, although the quantity of data in these plots is substantially less than

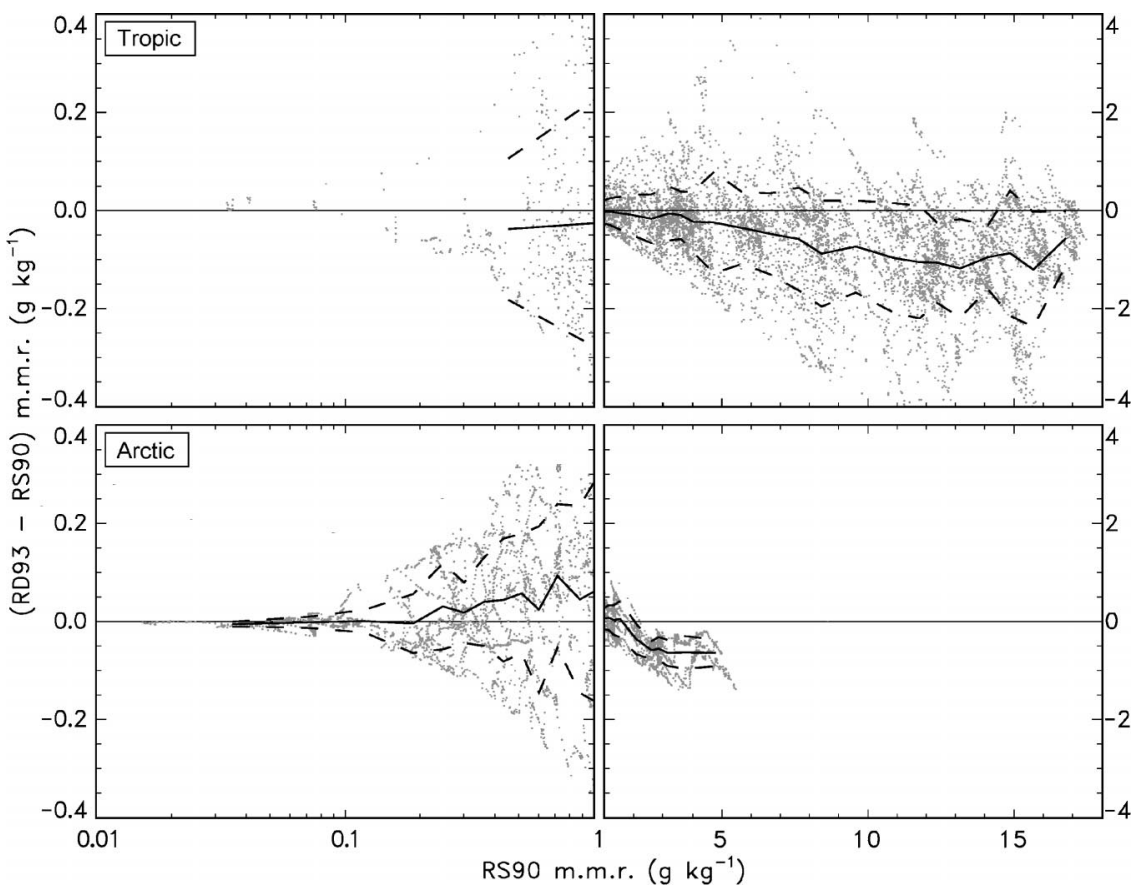

FIG. 3. Comparison of MOTH (top) Tropic and (bottom) Arctic RD93 and RS90 data. Tropic RD93s show reasonable agreement, although some dry bias is evident; Arctic data show significant dry bias at mixing ratios greater than $2 \mathrm{~g} \mathrm{~kg}^{-1}$. 

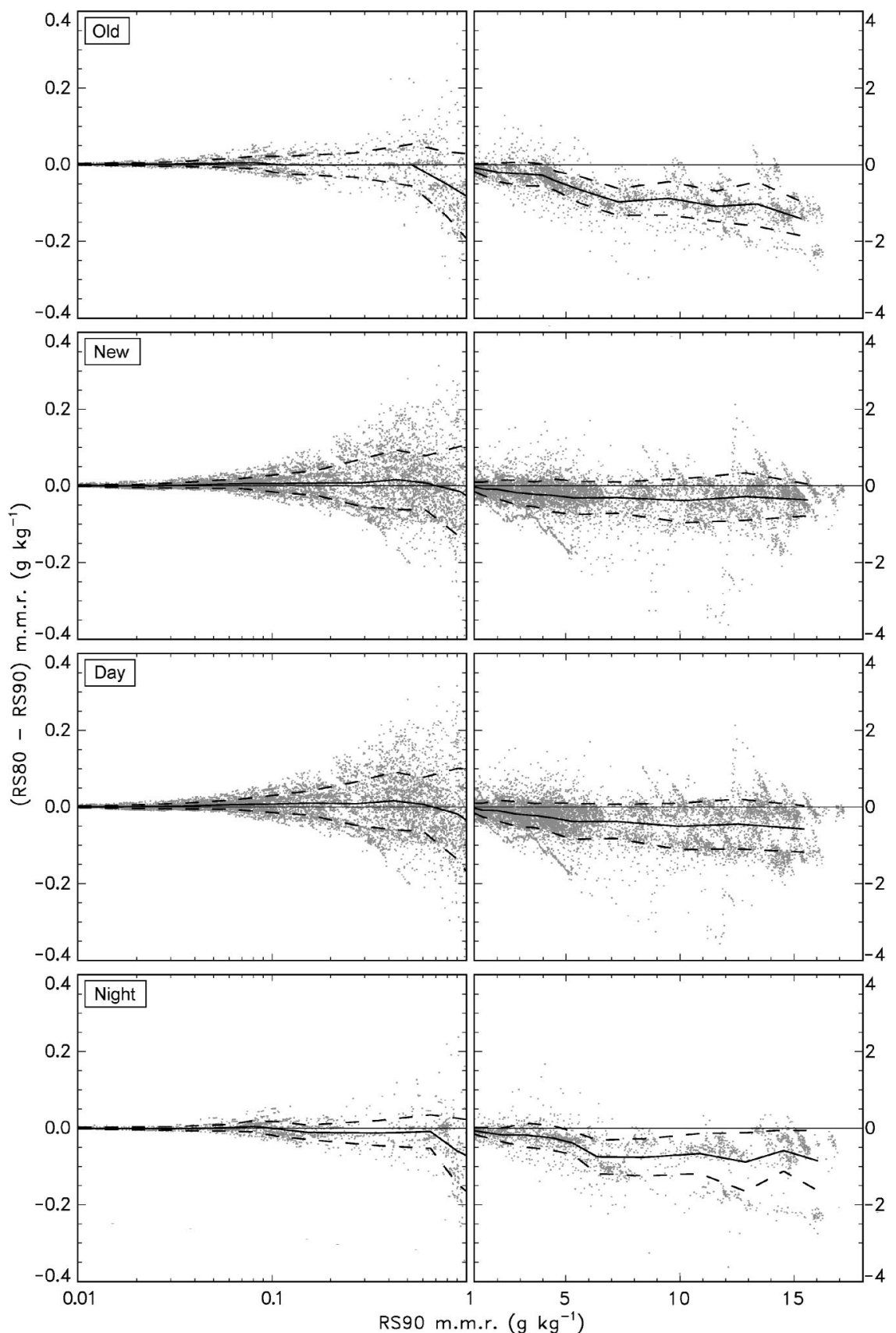

FIG. 4. Comparison of MOTH RS80 and RS90 data. (top) Old RS80s and (bottom) those flown at night show significant dry bias above 4 and $5 \mathrm{~g} \mathrm{~kg}^{-1}$, respectively. (second row) New RS80s and (third row) those flown by day show some dry bias but agree to $1 \sigma$.

above (Fig. 3, bottom row). The apparent dry bias exceeds $1 \sigma$ beyond $2 \mathrm{~g} \mathrm{~kg}^{-1}$, where it is approximately $15 \%$.

Overall, the means lie within 1 standard deviation of the line of 0 difference throughout the most of the range, but the dropsondes do appear to be reading some $7 \%$ drier than the balloon-borne RS90 sondes, with this difference approximating to $1 \sigma$ beyond $10 \mathrm{~g} \mathrm{~kg}^{-1}$.

\section{4) RS80 AND RS90 PROFILES}

Generally, although there seems to be a consistent tendency for the RS80s to exhibit a dry bias of about $5 \%$ with respect to the RS90s, the means lie within $1 \sigma$ of the 0-difference line throughout the range of mixing ratios encountered. This dry bias has been noted in laboratory tests (Balagurov et al. 1998). 


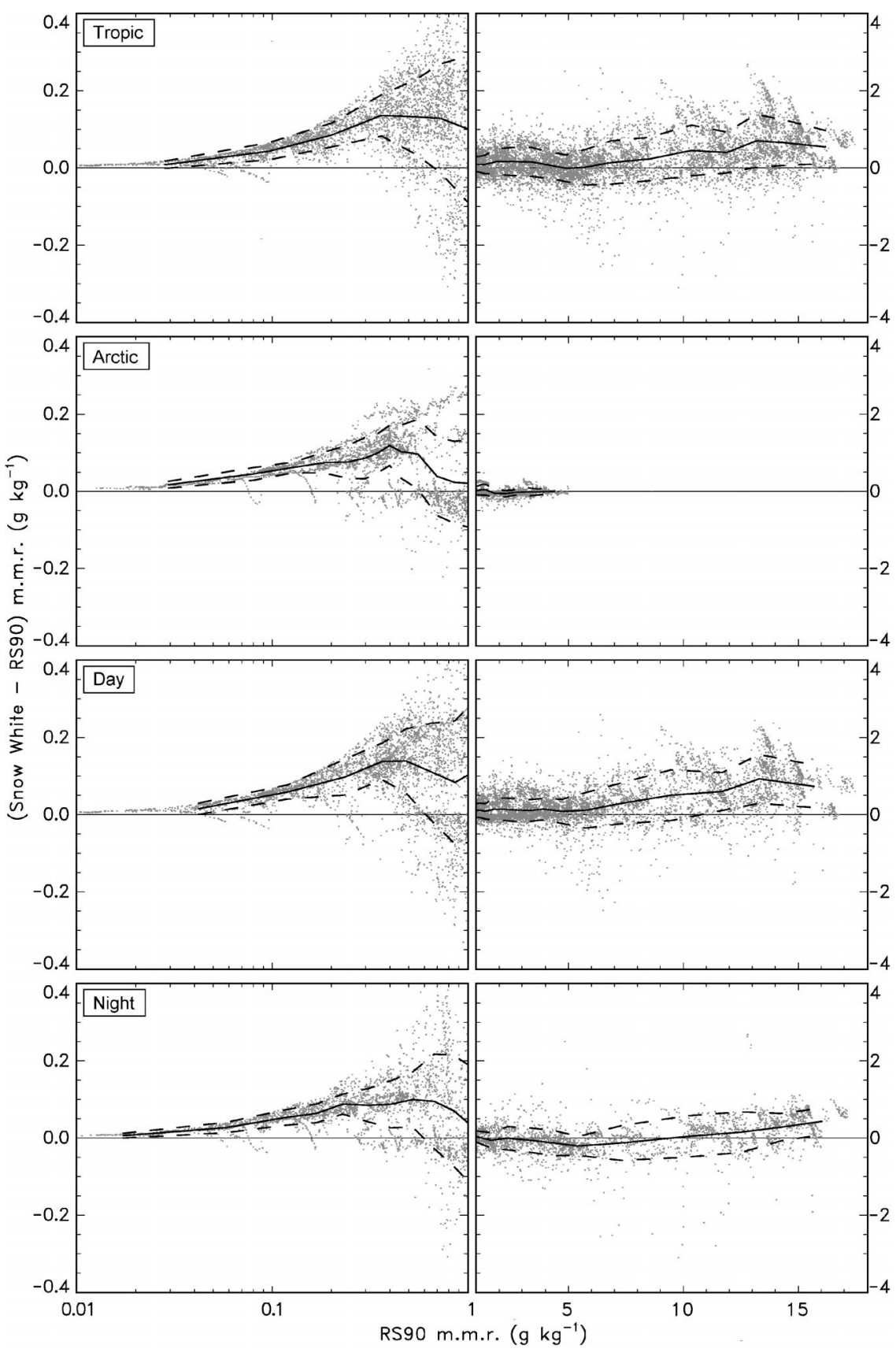

FIG. 5. Comparison of MOTH Snow White and RS90 data. (top) Tropic, (third row) day, and (bottom) night data show varying amounts of wet bias at higher mixing ratios, and all comparisons show significant wet bias below $0.6 \mathrm{~g} \mathrm{~kg}^{-1}$.

Although there is reasonable agreement at very low mixing ratios between the old RS80s and RS90s (Fig. 4 , top row), above $4 \mathrm{~g} \mathrm{~kg}^{-1}$ there is a serious discrepancy between the two instruments, with the old RS80s reading about $10 \%$ below the RS90. Other researchers have noted low measurements from RS80s (Lorenc et al. 1996; Nash et al. 1995) and that time since calibration is a significant issue (Lesht 1998) in the use of RS80 radiosondes, due to the Humicap element becoming contaminated by outgassing from the radiosonde and its packing material (Jaubert et al. 1999; Westwater et al. 2000). New RS80s (Fig. 4, second row) show better agreement with the RS90s, as expected, due to their more recent calibration date. They agree to $1 \sigma$ with the RS90 sondes throughout the range but report lower humidities than the RS90s by about 3\%. This has been 


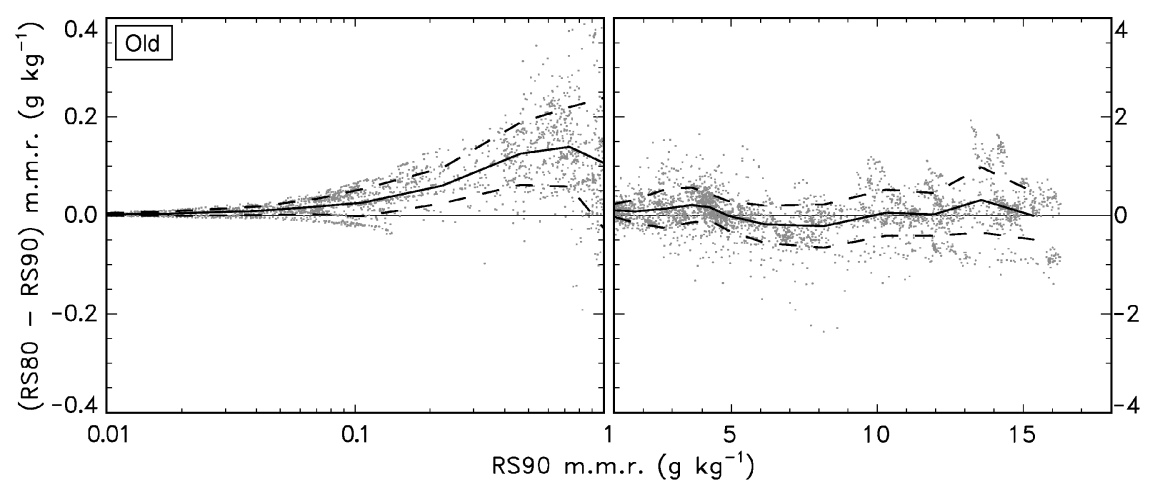

FIG. 6. Comparison of MOTH old RS80 data [corrected for age after Wang et al. (2003)] with RS90. Good agreement is seen above $1 \mathrm{~g} \mathrm{~kg}^{-1}$, but significant dry bias is evident at lower mixing ratios.

noted by others, and it is known that RS80s usually report $97 \%$ relative humidity in water cloud, not infrequently reading less than $95 \%$ relative humidity in such conditions (Nash et al. 1995).

When the data are partitioned according to whether the soundings were made before or after sunset, differences $(<1 \sigma)$ may be seen. In daylight soundings the RS80s still appear to show some evidence of a dry bias relative to the RS90s (Fig. 4, third row), but this is less than $1 \sigma$ throughout the range of mixing ratios encountered. With nightime soundings (Fig. 4, bottom row), however, the apparent dry bias in the RS80s is more pronounced, exceeding $1 \sigma$ beyond $5 \mathrm{~g} \mathrm{~kg}^{-1}$ and approximating to $5 \%$. The fact that the difference between the two instruments is less during daylight soundings than at night may be due, in part, to suspected deficiencies in the radiation correction that is applied to the humidity data from the RS90 sondes. The RS80 is less susceptible to the effects of insolation because its humidity sensor is covered by a reflective shroud, but sensor heating is still an issue of some debate (Nash et al. 2003; Wang et al. 2002).

\section{5) SNOW White AND RS90 PROFILES}

Overall, although the means are within $1 \sigma$ of the 0 difference line throughout most of the range of mixing ratios, there is an apparent wet bias in the Snow White at both the wettest and driest conditions encountered. The bias in MOTH Tropic data (Fig. 5, top row), at mixing ratios greater than $13 \mathrm{~g} \mathrm{~kg}^{-1}$, is approximately $5 \%$, while at mixing ratios below $0.4 \mathrm{~g} \mathrm{~kg}^{-1}$ it exceeds $30 \%$. These biases are believed to be largely due to the heater on board the Snow White being unable to fully clear the mirror at cold upper levels and at low levels in hot, humid conditions (W. Davies 2000, personal communication). MOTH Arctic data (Fig. 5, second row) show good agreement at mixing ratios greater 0.6 $\mathrm{g} \mathrm{kg}^{-1}$, but the tendency of the Snow Whites to show wet bias becomes significant $(1 \sigma)$ at mixing ratios less than this, but this is somewhat less than in Tropic com- parisons. That the Arctic data show better agreement than the Tropic supports the belief that the wet bias is due to inadequate clearance of the mirror, since neither the hot, humid surface conditions nor the extreme cold at upper levels were encountered during this experiment. Where there is clear evidence of battery failure or the conditions were outside the operating range of the instrument, data have been removed from the analysis. Daytime comparisons (Fig. 5, third row) show higher mixing ratios relative to the $\mathrm{RS} 90$ s throughout the range with wet bias at high mixing ratios, becoming significant $(1 \sigma)$ at $11 \mathrm{~g} \mathrm{~kg}^{-1}$. By contrast, nighttime data (Fig. 5, bottom row) show agreement between 0.6 and $15 \mathrm{~g}$ $\mathrm{kg}^{-1}$. This better agreement between the RS90 and Snow White measurements at night is indicative of the dry bias caused by solar heating of the RS90 humidity sensor during the day.

\section{d. Discussion}

In daylight intercomparisons the RS90 measurements agree well with the TWC and the new RS80s, although the Snow White sondes appear to show wet bias at low and high mixing ratios, and the dropsondes show dry bias at high mixing ratios. Old RS80s show more pronounced dry bias, as noted by other researchers (Balagurov et al. 1998; Lorenc et al. 1996; Nash et al. 1995, 2003; Wang et al. 2002). In daytime intercomparisons all instruments, except for the TWC, appear to report higher mixing ratios relative to the RS90. A known problem with the RS90 is that solar heating of the humidity sensor causes the sonde to report lower humidities and so a correction is currently being developed to apply to the daytime data (Nash et al. 2003). Snow White sondes are not affected by solar heating, so no difference between day and night soundings should be seen. Comparing the day/night differences between the Snow White/RS90 and new RS80/RS90 comparisons suggests that the RS90s read some 3\%-4\% lower during the day than during the night and that the new RS80s read some $2 \%-3 \%$ lower. These figures, although slight- 
ly larger, are in keeping with the findings of Smout et al. (2001) and suggest that the daytime radiation correction has not fully solved this problem. Although the RS80 is less susceptible to solar heating, it is not unaffected. The dry bias due to the RS80 sensors ageing and the greater solar heating effect on the RS90s will contribute to the good agreement between the RS80s and RS90s by day. The good agreement under all conditions between the RS90s and TWC [not susceptible to solar heating due to its design and location outside the aircraft (Nicholls et al. 1990)] argues against this interpretation; further work is required.

In a number of the Snow White profiles from the MOTH Arctic experiment, anomalously high mixing ratios were observed near the top of the ascent; this is believed to be due to failing batteries being unable to heat the mirror sufficiently to evaporate the frost (W. Davies 2000, personal communication). Battery failure on board the Snow White sondes, due to their relatively large power requirement, is a known problem (W. Davies and R. Maag 2003, personal communication), and data where there is clear evidence of this occurring have been removed, but this does not prevent the inclusion of all data where the mirror was not totally cleared; this is believed to be the reason for the large wet bias seen at upper levels in both experiments. Wet bias may also occur in the Snow White if the Peltier cooler is unable to sufficiently chill the mirror. Under these circumstances the control voltage in the Peltier circuit, from which the frost point temperature is derived, increases sharply, giving rise to an artificially high frost point. Although the Snow Whites appear to have been less susceptible to battery failure during MOTH Tropic, due to much of the ascent being in warmer conditions, the temperature at upper levels did, on occasions, fall below $-80^{\circ} \mathrm{C}$, the stated minimum operating temperature of the Snow White; these data were removed from the study. Current Snow White sondes are supplied with a higher-capacity battery than those used in the MOTH experiments, but work is ongoing to deal with the continuing problem of voltage drop caused by low temperatures (R. Maag 2003, personal communication).

Wang et al. (2002) assess various sources of error in the RS80 sondes and propose a correction scheme. The effect of correcting the MOTH RS80s for ageing effects has been briefly investigated (Fig. 6) and was found in all cases to produce a noticeable improvement in the agreement between the RS80s and RS90s at mixing ratios greater than $1 \mathrm{k} \mathrm{kg}^{-1}$, but at mixing ratios below this the agreement was clearly reduced. These effects are most pronounced in comparisons with the old RS80s.

The smaller standard deviations of the MOTH Arctic data make biases more obvious than in the Tropic data. All instruments appear to report lower mixing ratios relative to the RS90s than in Tropic comparisons, suggesting that the RS90s were, in fact, reporting higher mixing ratios. This may support the hypothesis that the

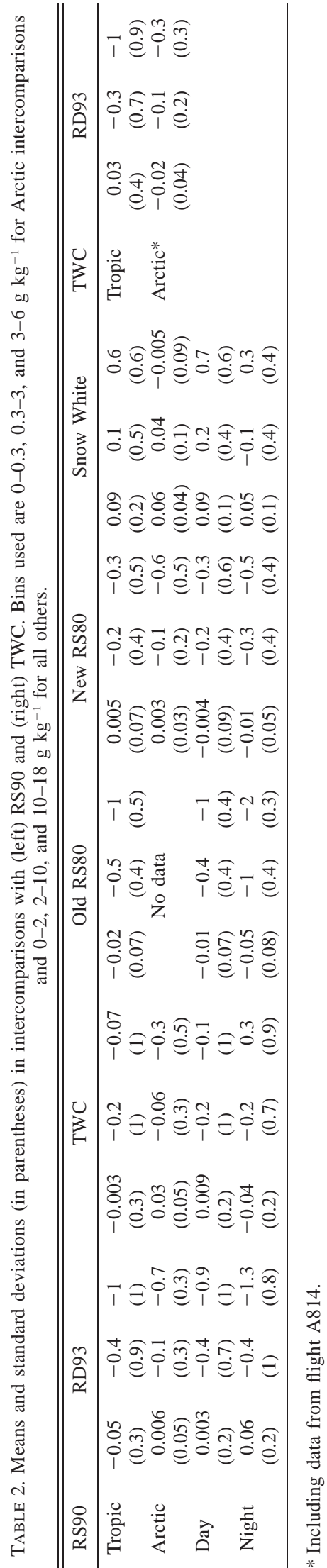




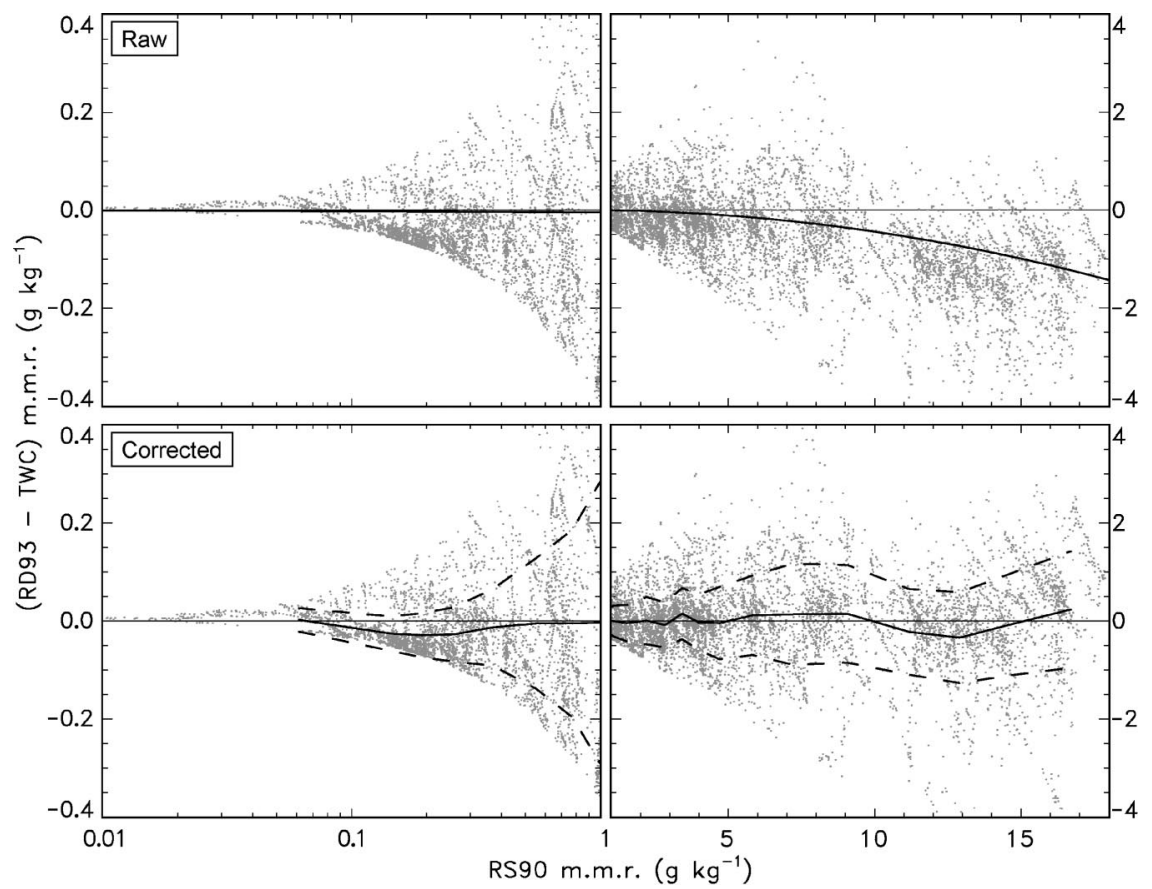

FIG. 7. (top row) Quadratic curve used to correct RD93 data overlaid on uncorrected RD93/ TWC comparison data. (bottom row) Comparison of TWC and corrected RD93 data. Means (solid line) are seen within $1 \sigma$ (dashed) of the 0 -difference line at all mixing ratios.

radiation correction is inadequate, but the differences between the Tropic and Arctic data, and the biases seen in the Arctic comparisons, are generally not significant compared to the standard deviations of the Tropic data.

Table 2 gives a summary of MOTH Tropic, MOTH Arctic, day, and night comparisons in terms of the means and standard deviations in three bins. To adequately summarize the results it has been necessary to use different bins for MOTH Tropic and Arctic data because of the differing ranges of mixing ratios encountered.

\section{Empirical correction of dropsonde data}

An important result of this intercomparison is that the RD93 dropsondes used by the MRF report significantly lower humidities than other instruments. This finding has prompted the development of the empirical correction for the RD93 dropsonde data reported herein in order that dropsondes may be used as a surrogate for aircraft profiles. Examples of its use on selected profiles are presented.

\section{a. Empirical correction}

The two sets of mass mixing ratio data were plotted as dropsonde-minus-TWC versus TWC (as in Fig. 2) and the "best fit" quadratic curve calculated for these data. This best-fit curve was used as the basis for the development of an empirical correction scheme correction. The equation

$$
\mathrm{mmr}_{1}=\mathrm{mmr}_{0}-\left(-4.4 \mathrm{mmr}_{0}^{2}-0.05 \mathrm{mmr}_{0}\right),
$$

where $\mathrm{mmr}_{0}$ represents the original mixing ratio and $\mathrm{mmr}_{1}$ represents the corrected mixing ratio, was found to remove the dry bias shown in the RD93 dropsonde data relative to the TWC. Figure 7 (top row) shows the curve used to correct the dropsonde data, overlaid on the uncorrected data, as shown in Fig. 2. The bottom plots in Fig. 7 are equivalent to Fig. 2 but with the dropsonde data corrected according to Eq. (1). Good agreement can be seen throughout the range of mixing ratios, as expected.

\section{b. Effect of empirical correction}

The result of applying this correction to individual dropsonde profiles is illustrated in Fig. 8, which shows the effect of the correction of the dropsonde data on a profile intercomparison from MOTH Tropic flight A670. The figure shows (left) the vertical profile as measured with the TWC (thick line) and the corrected dropsonde profile (thin line), and (right) the difference between the corrected and uncorrected dropsonde profiles. The dropsonde profile can be seen to agree well with the TWC over most of the profile, having been corrected by over $1 \mathrm{~g} \mathrm{~kg}^{-1}$ at moist, lower levels. From this study it may be concluded that the TWC data and that from the dropsondes (corrected as described in section 3a) are in agreement $(1 \sigma)$ to approximately $\pm 1 \mathrm{~g} \mathrm{~kg}^{-1}$ and that these limits are due to atmospheric factors rather than instrumental ones. 


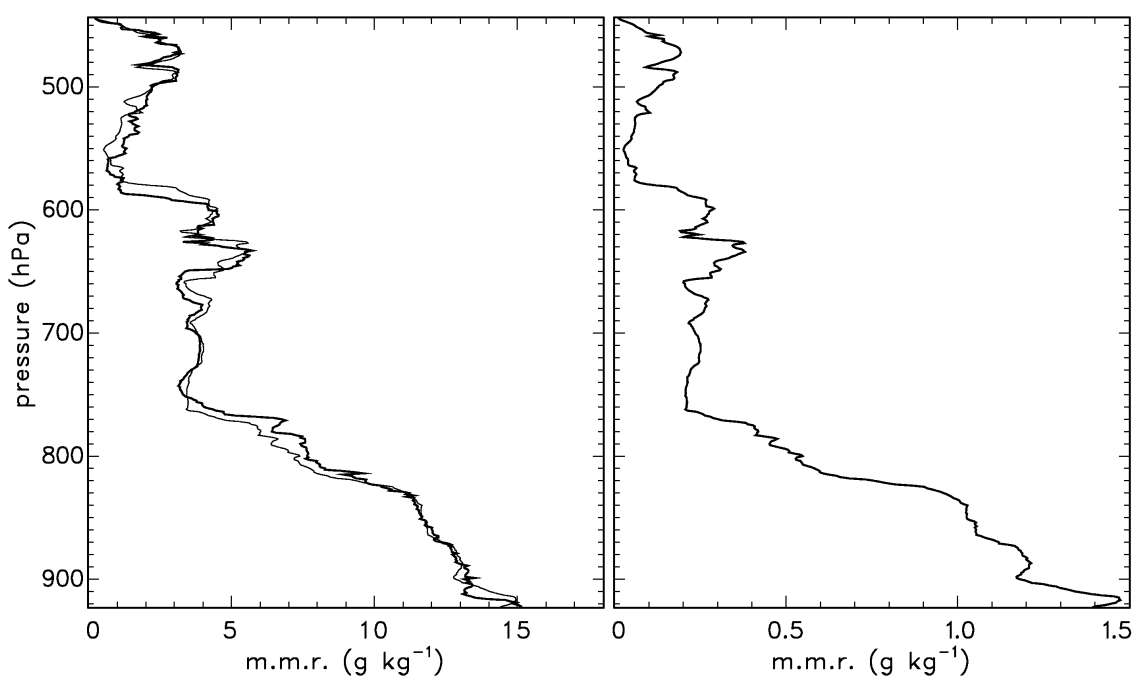

FIG. 8. Illustration of effect of proposed correction on one comparison from MOTH Tropic. (left) Profile from TWC (thick line) and corrected RD93 (thin); (right) difference between corrected and raw RD93 profiles.

\section{c. Effect of empirical correction on independent intercomparison}

A subsequent flight, A816, not included in the above dataset, included a specific comparison between the C130 and RD93 dropsondes; here we show the effect of applying the proposed correction to these data. At 1300 UTC four dropsondes were launched within $20 \mathrm{~s}$ of each other from approximately $7.4 \mathrm{~km}$. The aircraft then descended in the vicinity of the dropsondes in a series of straight legs to an altitude of $15 \mathrm{~m}$ at 1333 UTC. Three of the dropsondes reached the sea surface at 1309 UTC and the fourth, having a larger parachute, at 1319 UTC. Comparison of the temperature and humidity traces from the aircraft and all four dropsondes support the belief that all measured the same air structures.

Figure 9 shows plots equivalent to those in Figs. 2 and 7, with the left panel showing the difference between the four uncorrected dropsondes and the TWC mass mixing ratio, and the right panel showing the same data after the correction has been applied to the dropsonde data. The solid line in each case denotes the binned means of the data, with the dashed lines showing these plus and minus 1 standard deviations, as before. The figure following (Fig. 10) shows the effect of the correction on the profile from one dropsonde.

It is clear from Figs. 9 and 10 that the proposed correction has produced a significant improvement in the agreement between the aircraft and the dropsonde data.

\section{Conclusions}

We have presented results from two field experiments comparing a number of in situ humidity measurements.

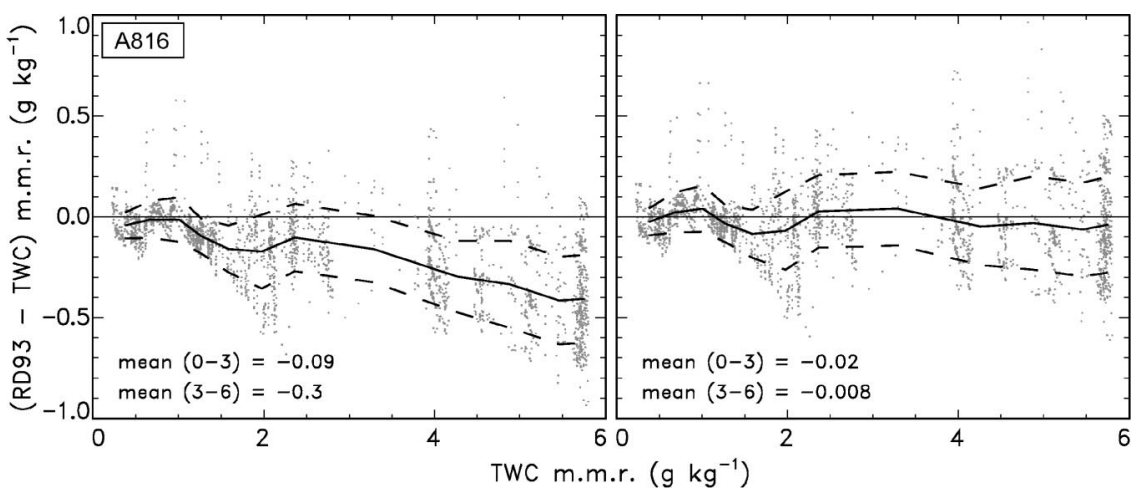

FIG. 9. Illustration of effect of proposed correction on RD93-TWC comparisons from flight A816. (left) Comparison with raw RD93 data; (right) corrected data. In each case means are indicated by the solid line, $\pm 1 \sigma$ by dashed lines. In the corrected case good agreement can be seen at all values, and mean differences have been greatly reduced compared to the raw comparison. 


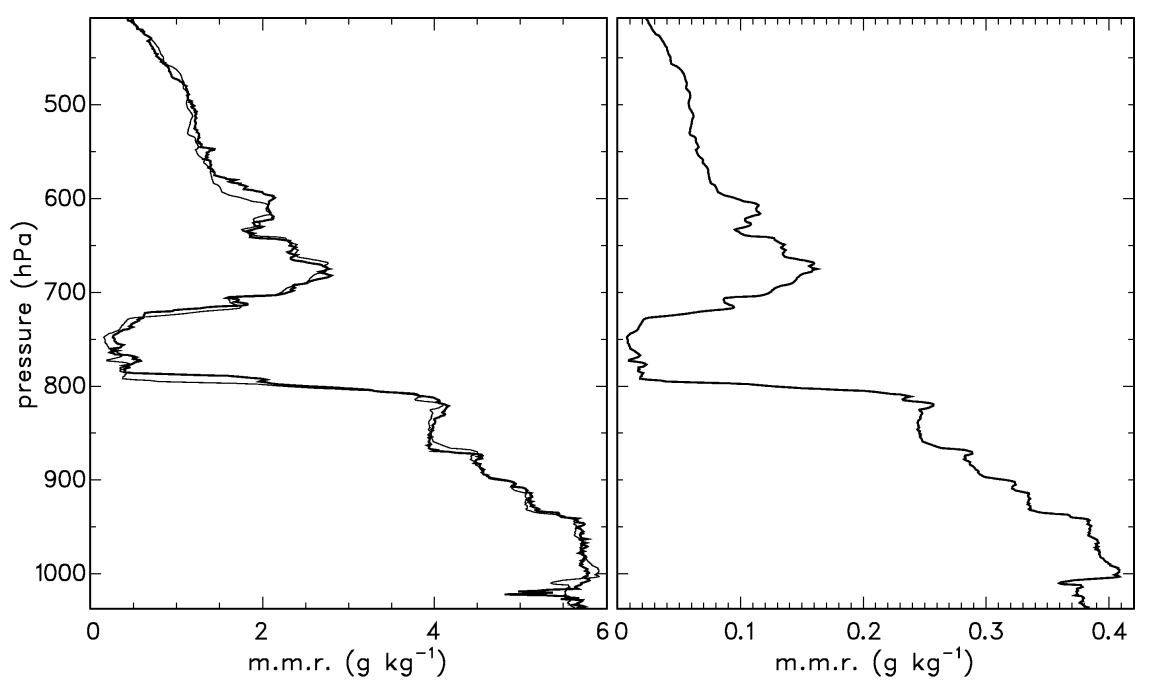

FIG. 10. Illustration of effect of proposed correction on one comparison from flight A816. (left) Profile from TWC (thick line) and corrected RD93 (thin); (right) difference between corrected and raw RD93 profiles. Good agreement can be seen at most levels.

We have shown there to be agreement $(1 \sigma)$ between the TWC and balloon-borne RS90 and "new" RS80 radiosondes (calibrated January 1999). It has been found that the Snow White radiosondes have a tendency to exhibit wet bias at high and low mixing ratios, agreeing only in midrange. Possible reasons for this have been discussed. "Old" RS80 radiosondes (calibrated March 1997) show the dry bias noted by others (Lorenc et al. 1996; Nash et al. 1995; Lesht 1998; Jaubert et al. 1999; Westwater et al. 2000). The effect of the age correction described in Wang et al. (2002) was briefly investigated and shown to improve agreement at mixing ratios above $1 \mathrm{~g} \mathrm{~kg}^{-1}$.

Intercomparisons between the RS90 and the RS80 and Snow White suggest that the RS80s and RS90 reports lower mass mixing ratios in daylight than nighttime soundings, while comparisons with the RD93 and the Snow White show higher mass mixing ratios being reported during MOTH Arctic than during MOTH Tropic. Both of these support the belief that the issue of solar heating of the RS80 and RS90 sensors requires further investigation.

Intercomparison of the TWC and the RD93 dropsondes show the dry bias reported by various researchers (e.g., Jaubert et al. 1999). An empirical correction, derived for use with MOTH data, is described and has been shown to produce good results with that dataset and in profiles from a non-MOTH aircraft/dropsonde intercomparison, but the problem of dry bias in RD93 dropsondes is one that requires further investigation. Dropsonde data (corrected as described in section 3a) has been shown to agree to better than $1 \mathrm{~g} \mathrm{~kg}^{-1}$ with TWC data from the MOTH experiments (this limit is due to atmospheric factors rather than instrumental ones) and to better than $0.3 \mathrm{~g} \mathrm{~kg}^{-1}$ in a separate intercomparison.
The mass mixing ratio correction described herein has been developed for clear-air use only and, although the errors seen in the dropsonde data in this case are typical of that seen by other researchers, its use on cloudy data may not be appropriate; this should be made clear to potential users of this correction scheme. If the vertical distribution of cloud in the sonde profile is well known, it may be possible to use this as a means of "recalibrating" the sonde for that particular descent by assuming that the relative humidity in the cloud is $100 \%$. This method of recalibrating dropsondes has not been investigated here because of a lack of suitable soundings.

The possibility of temperature measurement errors producing errors in the relative humidities reported by the RD93 sondes has been investigated (A. K. Vance 2004, unpublished manuscript), and we conclude that although errors of up to $3 \% \mathrm{RH}$ may exist from this source, which is a concern, this is not significant compared to those likely to arise from atmospheric variability.

Acknowledgments. The authors would like to acknowledge the staff of the Meteorological Research Flight, the Royal Air Force aircrew, the authorities at Ascension Island, Kalmar, and Visby, and the Met Office radiosonde team, who supported us during the MOTH experiments. Thanks are also due to Steve Devereau and Hal Cole for helpful discussions.

\section{REFERENCES}

Amstrup, B., and X.-Y. Huang, 1999: Impact of additional FASTEX radiosonde observations on the High-Resolution Limited-Area Model (HIRLAM) data-assimilation and forecasting system. Quart. J. Roy. Meteor. Soc., 125, 3359-3374.

Anderson, S. R., M. J. Bader, and R. K. Dumelow, 2000: The impact of UK radiosonde data on mesoscale model forecasts. Proc. Sec- 
ond CGC/WMO Workshop on the Impact of Various Observation Systems on Numerical Weather Prediction, Toulouse, France, World Meteorological, Organization, World Weather Watch Tech. Rep. 19, 191-198.

Baker, C. B., and R. E. Eskridge, 2000: Evaluation of aircraft (ACARS) data as a substitute for radiosonde data: Climate perspective. Preprints, Fourth Symp. on Integrated Observation Systems, Long Beach, CA, Amer. Meteor. Soc., 14-20.

Balagurov, A., A. Kats, and N. Krestyannikova, 1998: Implementation and results of WMO radiosondes humidity sensors intercomparison-Phase I "Laboratory Test." Proc. WMO Technical Conf. on Meteorological and Environmental Instruments and Methods of Observation (TECO-98), Casablanca, Morocco, World Meteorological Organization, WMO Instruments and Observing Methods Rep. 70, 181-184.

Cardinali, C., 2000: An assessment of using dropsonde data in numerical weather prediction. Proc. Second CGC/WMO Workshop on the Impact of Various Observation Systems on Numerical Weather Prediction, Toulouse, France, World Meteorological Organization, World Weather Watch Tech. Rep. 19, 131-141.

Elliott, W. P., and D. J. Gaffen, 1991: On the utility of radiosonde humidity archives for climate studies. Bull. Amer. Meteor. Soc., 72, 1507-1520.

Garand, L., C. Grasotti, J. Halle, and G. L. Klein, 1992: On differences in radiosonde humidity-reporting practices and their implications for numerical weather prediction and remote sensing. Bull. Amer. Meteor. Soc., 73, 1417-1423.

Gérard, É., and R. W. Saunders, 1999: Four-dimensional variational assimilation of Special Sensor Microwave/Imager total column water vapour in the ECMWF model. Quart. J. Roy. Meteor. Soc., 125, 3077-3101.

Guichard, F., D. Parsons, and E. Miller, 2000: Thermodynamic and radiative impact of the correction of sounding humidity bias in the Tropics. J. Climate, 13, 3611-3624.

Hock, T. F., and J. L. Franklin, 1999: The NCAR GPS dropwindsonde. Bull. Amer. Meteor. Soc., 80, 407-420.

Jaubert, G., C. Piriou, S. M. Loehrer, A. Petitpa, and J. A. Moore, 1999: Development and quality control of the FASTEX data archive. Quart. J. Roy. Meteor. Soc., 125, 3165-3188.

Leiterer, U., H. Dier, and T. Naebert, 1997: Improvements in radiosonde humidity profiles using RS80/RS90 radiosondes of Vaisala. Beitr. Phys. Atmos., 70, 319-336.

Lesht, B. M., 1998: Uncertainty in radiosonde measurements of temperature and relative humidity estimated from dual-sonde soundings made during the September 1996 ARM water vapor IOP. Preprints, 10th Symp. on Meteorological Observations and Instromentation, Phoenix, AZ, Amer. Meteor. Soc., 80-83.

Lorenc, A. C., D. Barker, R. S. Bell, B. MacPherson, and A. J. Maycock, 1996: On the use of radiosonde humidity observations in mid-latitude NWP. Meteor. Atmos. Phys., 60, 3-17.

McGrath, A. J., and T. J. Hewison, 2001: Measuring the accuracy of a Microwave Airborne Radiometer (MARSS). J. Atmos. Oceanic Technol., 18, 2003-2012.

Meteolabor, cited 2001: Water vapour measurement in troposphere and lower stratosphere. [Available online at http://www.meteolabor $\mathrm{ch} /$ datasheet/meteo/sw35e.pdf.]

Nash, J., J. B. Elms, and T. J. Oakley, 1995: Relative humidity performance observed in recent international radiosonde comparisons. Preprints, Ninth Symp. on Meteorological Observations and Instrumentation, Charlotte, NC, Amer. Meteor. Soc., 43-48.

_ _ T. J. Oakley, and C. Gaffard, 2003: Progress in improving upper air moisture measurements over the UK. Preprints, 12th Symp. on Meteorological Observations and Instrumentation, Long Beach, CA, Amer. Meteor. Soc., 8.5.

Nicholls, S., J. Leighton, and R. Barker, 1990: A new fast response instrument for measuring total water content from aircraft. $J$ Atmos. Oceanic Technol., 7, 706-718.

Smout, R., J. Elms, D. Lyth, and J. Nash, 2001: New technology in upper air observations. Proc. WMO Technical Conf. on Meteorological and Environmental Instruments and Methods of $\mathrm{Ob}$ servation (TECO-2001), Beijing, China, World Meteorological Organization, 179-182.

Ström, J., R. Busen, M. Quante, B. Guillemet, P. R. A. Brown, and J. Heintzenberg, 1994: Pre-EUCREX intercomparison of airborne humidity measuring instruments. J. Atmos. Oceanic Technol., 11, 1392-1399.

Szunyogh, I., Z. Toth, K. A. Emanuel, C. H. Bishop, C. Snyder, R. E. Morss, J. Woolen, and T. Marchok, 1999: Ensemble-based targeting experiments during FASTEX: The effect of dropsonde data from the lear jet. Quart. J. Roy. Meteor. Soc., 125, 31893217.

,-- , R. E. Morss, S. J. Majumdar, B. J. Etherton, and C. H. Bishop, 2000: The effect of targeted dropsonde observations during the 1999 winter storm reconnaissance program. Mon Wea. Rev., 128, 3520-3537.

Vaisala, cited 2002a: RD93 GPS dropwindsonde and aircraft data system. [Available from Vaisala Oyj, P.O. Box 26, FIN00421 Helsinki, Finland.]

__ , cited 2002b: RS90 radiosondes. [Available from Vaisala Oyj, P.O. Box 26, FIN-00421 Helsinki, Finland.]

_ , cited 2002c: Technical information. [Available from Vaisala Oyj, P.O. Box 26, FIN-00421 Helsinki, Finland.]

Wang, J., H. L. Cole, D. J. Carlson, E. R. Miller, K. Beierle, A. Paukkunen, and T. K. Laine, 2002: Corrections of humidity errors from the Vaisala RS80 radiosonde-Application to TOGA COARE data. J. Atmos. Oceanic Technol., 19, 981-1002.

Weckworth, T. M., V. Wulfmeyer, R. M. Wakimoto, R. M. Hardesty, J. W. Wilson, and R. M. Banta, 1999: NCAR-NOAA lowertropospheric water vapor workshop. Bull. Amer. Meteor. Soc., 80, 2339-2357.

Westwater, E. R., B. B. Stankov, Y. Han, J. A. Shaw, C. N. Long, B. M. Lesht, and J. Shannahoff, 2000: Comparison of microwave radiometers and radiosondes during the Nauru-99 experiment. Proc. IGARSS 2000, Piscataway, NJ, IEEE, 3024-3026.

Wilson, S. H. S., N. C. Atkinson, and J. A. Smith, 1999: The development of an airborne infrared interferometer for meteorological sounding studies. J. Atmos. Oceanic Technol., 16, 19121927. 